\title{
Fatigue Crack Growth on Double Butt Weld with Toe Crack of Pipelines Steel
}

\author{
Féthi Hadjoui $^{1}$, Mustapha Benachour ${ }^{1}$, Mohamed Benguediab ${ }^{2}$
}

${ }^{1}$ Mechanical Engineering Department, Faculty of Technology, University of Tlemcen, Tlemcen, Algeria; ${ }^{2}$ Mechanical Engineering Department, Faculty of Technology, University of Sidi Bel Abbes, Sidi Bel Abbes, Algeria.

Email: hadjoui_fethi@yahoo.fr

Received May $28^{\text {th }}, 2012$; revised June $29^{\text {th }}, 2012$; accepted July $30^{\text {th }}, 2012$

\begin{abstract}
The welded structures have a broad applicability (car industry, aeronautical, marine, pipelines, etc.). The welding being an assembled process, presents both advantages and disadvantages. A simple existing defect after welding can generate a catastrophic fracture. This work studies the fatigue crack growth of double butt weld with toe crack. Two types of pipeline material are studied with knowing API 5L grades X60 and X70 where tension form of loading is applied. In order to predict the fatigue behavior of the welded structure, a constant amplitude loading is applied where the influence of the stress ratio over the fatigue life is presented.
\end{abstract}

Keywords: Fatigue Crack Growth; Welding; Pipeline Material; Stress Ratio

\section{Introduction}

Today, most of the steel structures in engineering are fabricated by welding. These welded structures are often subjected to dynamic service loads. Welding present the primary jointing method used in gas and oil pipelines. Welded structures such as offshore structures, pressure vessels and pipelines, are affected by fatigue loading. The fatigue behavior of these welded structures is complicated by many factors intrinsic to the nature of welded joints. Many defects may be introduced in welded joints such as lack of penetration at the weld root, undercutting at weld toes, gas pores, etc. Near the defects zones stress concentrations arise and favorite by the presence of residual stress. Fatigue assessment procedures for welded structures presented in reviewed work [1] have shown that the cumulative damage under realistic stress affect the fatigue limit. Frank [2] has shown that two types of cracking will normally cause failure of a fillet welded joint. They are root cracking and toe cracking.

Experimental fatigue tests of welded structures for the national research institute of metal [3] have shown that the fatigue failure origin change with the magnitude of the stress range. Based on these tests, the fatigue crack originated from the weld root when the stress range was large and from the weld toe when the stress range was small. Recently, Kainuma and Mori [4] have shown the reason of change in origin of fatigue of weld structures in our work. In welding operation, the presence of defects in welded pipelines can be generated by damage during the operating time. Most pipelines, used under stop and start working conditions [5], are subjected to the low cycle fatigue load [6].

The effect of butt weld geometry parameters (weld toe, flank angle, plate thickness, initial crack geometry) on the fatigue crack propagation life have been studied by Nguyen and Wahab [7] by using Linear Elastic Fracture Mechanics (LEFM). In other work, Nguyen and Wahab [8] developed a mathematical model to predict the overall effect of the influencing weld geometry parameters such as (e.g. weld toe radius, weld toe undercut, plate thickness, etc.) and residual stresses on the fatigue strength and fatigue life of butt-welded joints subjected to combined loading (tensile and bending). It has been demonstrated that the co-influence effect of weld toe-undercut with other buttweld geometry parameters is very significant. In particular, fatigue crack growth behavior of welded joints depends on the geometric configurations of the weld and plate thickness [9].

Many studies [10,11] estimated the fatigue crack propagation life of the weldment based on the fracture mechanics model and discussed the influence of the radius at the weld toe. In the investigation conducted by Nykänen et al. [12], the toe cracks initially perpendicular to the plates, an initial crack length " $a_{i}$ " of $0.2 \mathrm{~mm}$ was assumed. This length is typical when arc welding is used.

Moreover, several pipelines materials have been studied in the received or cutting in pipelines tubes with the effects of several parameters. The effects of tough- 
ness on both the fatigue crack propagation rate (FCPR) and the constant amplitude low cycle fatigue for low carbon micro-alloyed pipeline steels (X60, X70, etc.) with various microstructures and toughness are studied by Zhong et al. [13]. The results indicate that the fatigue crack growth rate and fatigue life were affected by increasing of toughness. Under the same load, the fatigue life is greater for X70 to X60. In Fazzini et al. (2007) work, pipeline material X52 was studied. Fatigue tests were carried out to characterize propagation of fatigue cracks in weld metal, it was found that a large Paris exponent made the few large amplitude cycles most contributing to crack propagation. In research laboratory, many pipelines materials are investigated. Fatigue X65 was studied by Duffet [14] and Mokhdani [15]. The fatigue behavior is affected by compressive residual stress induced by mechanical preloading when the Paris's law is applied. The crack propagation characteristics of X70 pipeline steel under cyclic loading are investigated by Mingxing et al. [16]. The results indicate that the crack propagation is controlled mainly the crack type stress intensity factor range $\Delta K$. but the stress ratio has no effect on the crack propagation rate in the synthetic high soil solution $(\mathrm{pH}=9.3)$. Benachour et al. [17] have presented the effect of stress ratio on fatigue crack growth of double fillet weld. Other parameters have been investigated (initial crack length, angle of weld and the range of the applied load). Results have shown that the fatigue life is affected considerably by these parameters.

The main objective of this work is to study the two pipelines materials X60 and X70 under constant amplitude loading for double butt weld with toe crack under the effects of loading parameters (stress ratio) and thickness of welded specimen. The paper is organized as follow: Section 2 presents studies material and introduces fatigue crack growth simulation. Section 3 presents results and discussion. Section 4 gives conclusions.

\section{Fatigue Crack Growth Simulation}

\subsection{Materials and Specimen}

Materials used in this study are the API 5L grades X60 and X70, subjected to numerical fatigue tests. The basic mechanical properties for theses materials are given in Table 1. The test specimen, double butt weld plate with toe crack, is shown in Figure 1.

\subsection{Fatigue Crack Growth Model}

The estimation of the fatigue life of welded structures is complicated by large variations in weld geometry, welding defects, residual stress, etc. The crack propagation is the dominant part of the fatigue life. In order to predict fatigue crack growth, several models were proposed by different researchers. Among the proposed equations, the Paris's law [18] is commonly accepted and used in practice. The relationship between cyclic crack growth rate and the range of cyclic stress intensity factor is characterized by the materials parameters in Paris's law as shown in the following equation:

$$
\frac{\mathrm{d} a}{\mathrm{~d} N}=C \cdot \Delta K^{m}
$$

where: $\mathrm{d} a / \mathrm{d} N$ is the fatigue crack growth rate, " $C$ " and " $m$ " are materials constants and " $\Delta K$ " is the range of cyclic stress intensity factor. The model elaborated by Paris is recommended in practice [19] for the calculations of fatigue crack of welded joints made by steel. During service of pipeline, the internal pressure varies, which results in a cyclic hoop stress. The variations of internal pressures to the two limits $P_{\max }$ and $P_{\min }$ that generate fatigue damage with an variable stress ratio equivalent to the load stress $R=\sigma_{\min } / \sigma_{\max }$. The stress intensity factor in loading mode has the following form:

$$
\Delta K=\Delta \sigma \sqrt{\pi \cdot a} \cdot \beta
$$

Equation (2) can be rewritten in the following form to allow for the effect of weld geometry and residual stress in loading mode, as follows:

$$
\begin{gathered}
K_{I}=\Delta \sigma \sqrt{\pi \cdot a} \cdot \beta_{0} \cdot M_{\text {keff }} \\
M_{\text {keff }}=\left(M_{k a}+M_{k, r} \cdot \frac{\sigma_{r}}{\Delta \sigma}\right)
\end{gathered}
$$

where $\sigma_{r}$ : Maximum residual stress.

$M_{\text {keff: }}$ Effective stress intensity magnification factor produced by weld profile geometry and residual stress in specified loading mode.

$M_{k a}$ : Stress intensity magnification factor produced by weld profile geometry in axial loading.

If the range of the stress intensity factor of a cracked body is known, the fatigue crack propagation life $N_{r}$ can be calculated by integrating Equation (1) between the initial

Table 1. Mechanicals properties of the steels [13].

\begin{tabular}{ccccc}
\hline Pipeline Steel & $\sigma_{0.2}(\mathrm{MPa})$ & $\begin{array}{c}\text { UTS } \\
(\mathrm{MPa})\end{array}$ & A (\%) & E (GPa) \\
\hline X60 & 454 & 519 & 29 & 206 \\
X70 & 560 & 660 & 25 & 206 \\
\hline
\end{tabular}

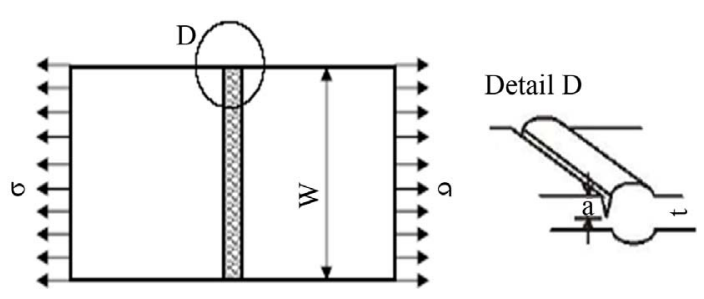

Figure 1. Double butt weld plate with toe crack. 
crack length " $a_{i}$ " and the final crack length at failure " $a_{f}$ ". In this study, the range of stress intensity factors is replaced by the range of effective stress intensity factors $\left(\Delta K_{\text {eff }}\right)$ to allow for the effect of the weld geometry and the residual stresses. For the considered materials, the coefficient of Paris's law model $C$ and $m$ are presented in Table 2. The number of cycles required to propagate a crack from an initial crack size " $a_{0}$ " to a final crack " $a_{f}$ " can be calculated by using the Equation (5) when numerical integration is applied.

$$
N_{f}=\int_{a_{0}}^{a_{f}} \frac{\mathrm{d} a}{C \cdot \Delta K^{m}}
$$

\section{Results and Discussion}

\subsection{Fatigue Crack Growth in X60 Material}

Double weld butt plate with toe crack was subject to a tensile constant amplitude loading. Initial crack and final crack are respectively 0.2 and $10 \mathrm{~mm}$. The final crack length fracture criterion is adopted for the limit of crack growth.

The variation of crack length " $a$ " VS number of cycle " $N$ " is plotted in Figure 2 for fatigue crack growth of pipeline material X60. In this figure, we show the effect of stress ratio on fatigue life $N_{f}$. As the stress ratio increases, the fatigue life increases. For the same maxmum applied load $(R=0.1$ and 0.2$)$, the results are in good agreement for the results of Srivastava and Garg [20]. A shift of fatigue life curve for $R=0.3$ is shown, this is due to the amplitude loading effect when maximum applied load are greater comparatively for $R=0.1$ and 0.2 . After

Table 2. Coefficients of Paris's law model.

\begin{tabular}{ccc}
\hline Pipeline Steel & $C$ & $m$ \\
\hline X60 & $3.0 \times 10^{-10}$ & 3.0 \\
X70 & $1.7 \times 10^{-11}$ & 3.4 \\
\hline
\end{tabular}

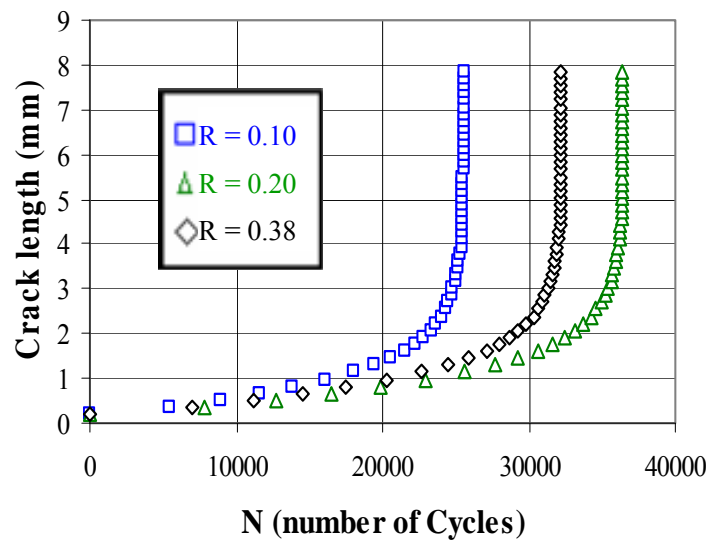

Figure 2. Effect of stress ratio on fatigue life for X60 pipeline material. crack length $4 \mathrm{~mm}$ and in different stress ratio, the crack growth with the same crack growth rate. The effect of thickness specimen is presented in Figure 3. With same final crack, we show a shift of fatigue curves. When thickness increases, fatigue life deceases. This is due to the effect of corrective of geometry and weld geometry function $\beta$ (see Equations (2) and (3)).

\subsection{Fatigue Crack Growth in X70 Material}

In API $5 \mathrm{~L}$ grade X70 material, the same specimen geometry is subjected to the same load $(R=0.1$ and 0.2$)$. We have shown the same effect of increasing of stress ratio (Figure 4) comparatively to the API 5L grade X60. Comparative study in fatigue life between the two materials is plotted in Figure 5. In this figure, we have shown an increasing of fatigue life in API 5L X70 pipeline materials. This evolution is due to crack growth rate interpreted by the slope $m$ and parameter $C$ in Paris's law model. These results prove that X70 pipeline materials present a good resistance to the fatigue crack growth comparatively to the X60 pipeline materials. The same conclusion is noticed in experimental investigation of Zhong et al. [13].

\section{Conclusion}

In this paper simulation of fatigue crack growth on double butt weld plate with toe crack of pipelines steel X60

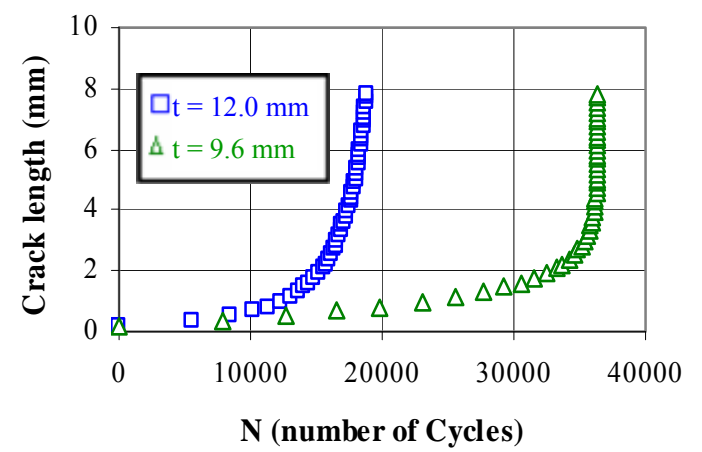

Figure 3. Thickness effect on fatigue crack growth life for X60 pipeline material.

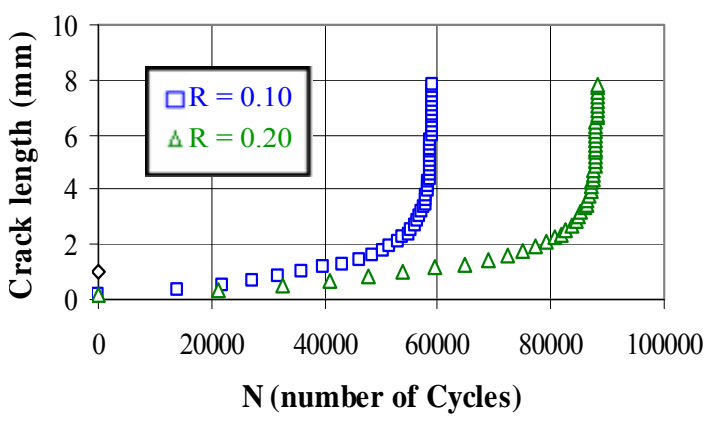

Figure 4. Effect of stress ratio on fatigue life for X70 pipeline material. 


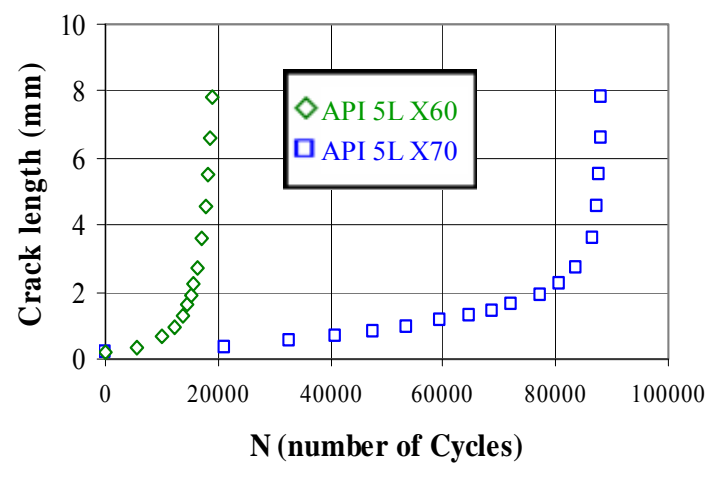

Figure 5. Comparison of fatigue life for API 5L X60 and X70 pipeline steel at $R=0.2$.

and X70 is investigated. Crack growth data show the influence of stress ratio. The fatigue life is affected by specimen thickness through the weld parameter geometry. Pipeline material steel API $5 \mathrm{~L}$ grade $\mathrm{X} 70$ present good resistance in fatigue crack growth comparatively to API $5 \mathrm{~L}$ grade X60. Resistance of this material (X70) is ameliorated high tensile stress.

\section{REFERENCES}

[1] S. J. Maddox, "Fatigue Strength of Welded Structures," Cambridge University Press, Abington, 1991.

[2] K. H. Frank, Journal of Structural Division, Vol. 105, 1979, pp. 1727-1739.

[3] NIRM, "Fatigue Data Sheet, No. 18: Data Sheets on Fatigue Properties for Load-Carrying Cruciform Welded Joints of SM50B Rolled Steel for Welded Structure," National Research Institute for Metals, 1980.

[4] S. Kainuma and T. Mori, "A Study on Fatigue Crack Initiation Point of Load-Carrying Fillet Welded Cruciform Joints," International Journal of Fatigue, Vol. 30, No. 9, 2008, pp. 1669-1677. doi:10.1016/j.ijfatigue.2007.11.003

[5] K. Kannan and J. P. Hirth, "Mixed Mode Fracture Toughness and Low Cycle Fatigue Behavior in an HSLA-80 Steel," Scripta Materialia, Vol. 39, No. 6, 1998, pp. 743748. doi:10.1016/S1359-6462(98)00185-7

[6] K. S. Chan, "Scaling Laws for Fatigue Crack," Metallurgical and Materials Transactions A, Vol. 24, No. 11, 1993 , pp. 2473-2486.

[7] T. N. Nguyen and M. A. Wahab, "A Theoretical Study of the Effect of Weld Geometry Parameters on Fatigue Crack Propagation Life," Engineering Fracture Mechanics, Vol. 51, No. 1, 1995, pp. 1-18.
[8] T. N. Nguyen and M. A. Wahab, "The Effect of Weld Geometry and Residual Stresses on the Fatigue of Welded Joints under Combined Loading," Journal of Materials Processing Technology, Vol. 77, No. 1-3, 1998, pp. 201208.

[9] J. A. M. Ferreira and C. M. Branco, "Influence of Weld and Plate Geometry on the Fatigue Strength of Cruciform Joints," Theoretical and Applied Fracture Mechanics, Vol. 9, No. 1, 1988, pp. 23-32. doi:10.1016/0167-8442(88)90044-4

[10] S. J. Maddox, Met. Construct., Vol. 2, No. 8, 1970, pp. 327-335.

[11] J. A. M. Ferreira and C. M. Branco, "Influence of the Radius of Curvature at the Weld Toe in the Fatigue Strength of Fillet Welded Joints," International Journal of Fatigue, Vol. 11, No. 1, 1989, pp. 29-36. doi:10.1016/0142-1123(89)90044-3

[12] T. Nykänen, X. Li, T. Björk and G. Marquis, “A Parametric Fracture Mechanics Study of Welded Joints with Toe Cracks and Lack of Penetration," Engineering Fracture Mechanics, Vol. 72, No. 10, 2005, pp. 1580-1609. doi:10.1016/j.engfracmech.2004.11.004

[13] Y. Zhong, Y. Shan, F. Xia and K. Yang, "Effect of Toughness on Low Cycle Fatigue Behavior of Pipeline Steels," Materials Letters, Vol. 59, No. 14-15, 2005, pp. 1780-1784.

[14] G. Duffet, "Mechanisms and Criteria of Steel Delamination Ferrito-Perletic Micro-Alloyed Low-Carbon Produced by Controlled Rolling," Doctorate Thesis, University of Franche-Conté, Paris, 1991.

[15] C. Mokhdani, "Initiation and Propagation of the Fatigue Cracks in a Steel for Tubes of Transport of Gas," Doctorate Thesis, Ecole des Mines de Paris, Paris, 1995.

[16] M. X. Li, R. Wang, P. L. Li and M. X. Lu, Journal of Chinese Society for Corrosion and Protection, Vol. 24, 2004, pp. 163-167.

[17] M. Benachour, M. Benguediab, A. Hadjoui, F. Hadjoui and N. Benachour, "Fatigue Crack Growth of a Double Fillet Weld," Computational Materials Science, Vol. 44, 2008, No. 2, pp. 489-495. doi:10.1016/j.commatsci.2008.04.015

[18] P. Paris and F. Erdogan, "A Critical Analysis of Crack Propagation Laws," Journal of Basic Engineering, Vol. 85, No. 4, 1963, pp. 528-534. doi:10.1115/1.3656900

[19] A. Hobbacher, "Fatigue Design of Welded Joints and Components," Abington Press, Abington, 1996.

[20] Y. P. Srivastava and S. B. L. Garg, "Influence of R on Effective Stress Range Ratio and Crack Growth," Engineering Fracture Mechanics, Vol. 22, No. 6, 1985, pp. 915-926. 